doi: 10.15407/ujpe60.08.0795

B. ESHCHANOV, SH. OTAJONOV, N. SOLIEVA, A. ISAMATOV

Department of Physics, National University of Uzbekistan

(Tashkent 100174,Uzbekistan; e-mail: bakhodir.eshchanov@gmail.com)

\title{
INTENSITY DISTRIBUTION IN THE SPECTRUM OF MOLECULAR LIGHT PACS 77.22.Ej, 78.35.+c SCATTERING AND RELAXATION EFFECTS IN LIQUIDS
}

\begin{abstract}
The structure and shape of the spectral bands of orientational molecular scattering of light in toluene are analyzed. The possibility of their use for obtaining information about the features of interactions of molecules is revealed. It is shown that the observed scattering regularities can be explained, by basing on the mechanism of hindered rotation of the molecules with regard for the specific intermolecular interaction in toluene.

Keywords: orientation spectroscopy, molecular scattering of light, orientation motion of molecules in liquids, relaxation mechanism, relaxation time, fluctuation.
\end{abstract}

\section{Introduction}

The problem of determining the nature and strength of intermolecular interactions in condensed media, as well as the most common regularities of changes in the optical spectra of molecular complexes, due to the influence of intermolecular interactions of different nature is the fundamental branch of modern condensed matter spectroscopy [1-7].

An intermolecular spectrum can be considered as a source of information on the specificity of the condensed state of matter, since it reflects the motion of molecules, intermolecular interactions, and the temperature variation of the structure of matter. Analysis of the experimental works shows that, with rare exceptions, they do not address the full range of the intermolecular spectrum over a wide temperature range. This work is devoted to the study of the temperature behavior of the depolarized component of the molecular scattering of light (DCMSL) over a wide temperature interval $20-200{ }^{\circ} \mathrm{C}$ and a frequency interval from 0 to $50-60 \mathrm{~cm}^{-1}$ in toluene. For this purpose, in accordance with certain assumptions, it is required to observe the thermal behavior of a number of parameters of the condensed state of matter; to analyze the possibility of obtaining information on the nature of the temperature change in the dynamics of movement and interaction of molecules of

(c) B. ESHCHANOV, SH. OTAJONOV, N. SOLIEVA,

A. ISAMATOV, 2015 matter and its structural changes on the temperature change of the DCMSL spectrum.

\section{The Experimental Part}

The DCMSL spectra were recorded on the experimental setup constructed on the base of a DFS12 spectrometer, which is used to obtain the spectra of weak signals operating in the photon counting mode. The description of the installation can be found in [8]. The substances used, depending on the grade of purity, were cleaned, dried, de-dusted, and outgassed by double vacuum distillation. The purity of the object was controlled by the relative intensities of the shifted and unshifted Mandelstam-Brillion components of the scattering polarized part.

\section{Results and Discussion}

The object of studies was toluene $\left(\mathrm{C}_{6} \mathrm{H}_{5} \mathrm{CH}_{3}\right)$ - asymmetric on the molecular polarizability. Data on the DCMSL spectrum of toluene are very limited. In particular, there are no data on the temperature dependence of the light scattering, on the shape of the spectrum, etc. The intensity distribution of highfrequency areas (50-200 $\mathrm{cm}^{-1}$ ) had previously been studied in [8]. As a result of the statistical processing of the distant areas of the recorded DCMSL contour by various analytical functions, it is shown that the best approximation corresponds to a Gaussian. Therefore, it was interesting to apply the dynamics of temperature changes for the low-frequency

ISSN 2071-0194. Ukr. J. Phys. 2015. Vol. 60, No. 8 


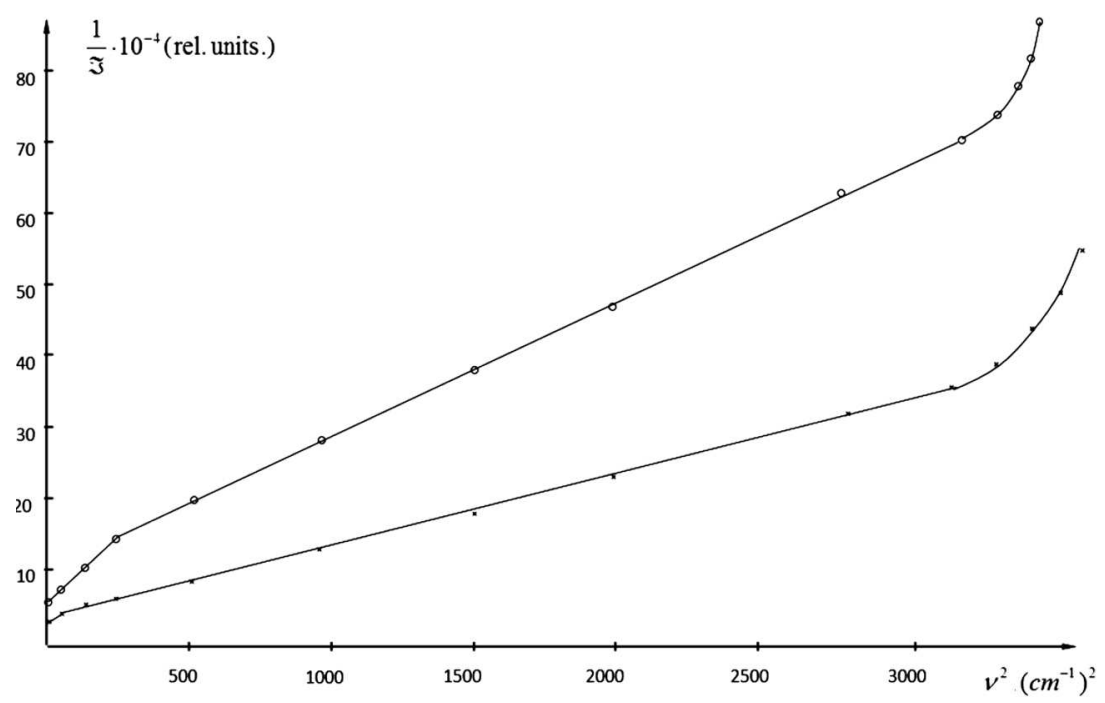

Fig. 1. Reciprocal spectral density of DCMSL lines in toluene molecules as a function of the squared frequency: at a temperature of $20{ }^{\circ} \mathrm{C}(1)$, at a temperature of $200{ }^{\circ} \mathrm{C}(2)$

region of the DCMSL spectrum of toluene to establish the mechanism of scattering in the frequency interval $0-50 \mathrm{~cm}^{-1}$.

Experiments show that the observed line contour in DCMSL (in the coordinates $1 / \mathfrak{J}-\nu^{2}$, where $\mathfrak{J}$ is the spectral density of the contour) represents the sum of two dispersive lines in the frequency interval $0-60 \mathrm{~cm}^{-1}$, with the interface between the components equal to about $15 \mathrm{~cm}^{-1}$ at the temperature $T=20^{\circ} \mathrm{C}$. With the heating, the dispersive line undergoes a further simplification, and the boundary of the band shifts toward lower frequencies, and this point is about $7 \mathrm{~cm}^{-1}$ at $T=200^{\circ} \mathrm{C}$ (Fig. 1).

Toluene is structurally related to an asymmetric top. According to the model of hindered rotation of molecules (MHRM) [5,9], the DCMSL contour is a superposition of three dispersion contours, whose halfwidths $\left(\sigma_{i}\right)$ are determined by three relaxation times $\tau_{i}, \sigma_{i}=\frac{1}{2 \pi c \tau_{i}}$, and the weight $\left(\alpha_{i}\right)$ is defined via the main value of the components for the molecule polarizability tensor

$\alpha_{i}=\frac{\left(a_{k}-a_{j}\right)^{2}}{2 \gamma^{2}}$,

where $\gamma^{2}=\frac{1}{2}\left[\left(a_{1}-a_{2}\right)^{2}+\left(a_{1}-a_{3}\right)^{2}+\left(a_{2}-a_{3}\right)^{2}\right]$ is the anisotropy of molecules, $a_{1}, a_{2}, a_{3}$ - the principal values of components of the polarizability tensor of a molecule.
According to MHRM, a contour in the liquids with non-axisymmetric molecules must consist of three Lorentzians. However, the structure of a toluene molecule allows suggesting that a Lorentz half-width $\sigma_{2}$ related to the rotation about the axis passing through the substituted vertices of the benzene ring $a_{1}$ (Fig. 2) should be much more than the half-widths of two other components. Furthermore, the theoretical value of contour weight $\alpha_{3}$ associated with the rotation about the third axis (the axis of symmetry for toluene) calculated in the "gas" approximation is much smaller than $\alpha_{2}$.

Because of this expansion, the DCMSL contour consisting of two, rather than three Lorentz components can be considered a reasonable approximation. Subsequently, the first contour means a sum of the first and third contours.

Table 1 shows the weights $\alpha_{1}^{\text {theor }}, \alpha_{2}^{\text {theor }}$, and $\alpha_{3}^{\text {theor }}$ calculated by formula (1). Data on the main values of polarizabilities are taken from [10]. As we can see from this table, the weight of the third contour $\alpha_{3}$ is very small (4\%), so the observed DCMSL contour can be represented as the sum of

Table 1

\begin{tabular}{|c|c|c|c|}
\hline Substance & $\alpha_{1}^{\text {theor }}$ & $\alpha_{2}^{\text {theor }}$ & $\alpha_{3}^{\text {theor }}$ \\
\hline $\mathrm{C}_{6} \mathrm{H}_{5} \mathrm{CH}_{3}$ & 0.61 & 0.35 & 0.04 \\
\hline
\end{tabular}




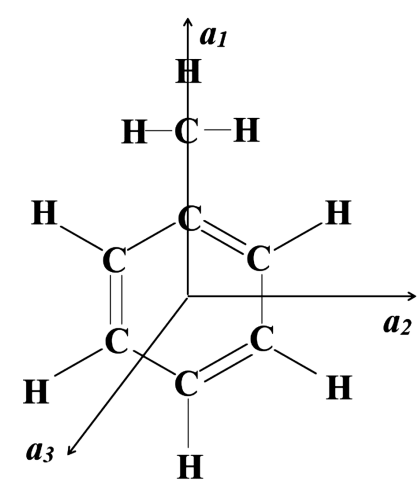

Fig. 2. Structural formula and the choice of axes of a molecule of toluene

the two dispersion (Lorentzian) contours ("narrow" in the frequency interval $0-15 \mathrm{~cm}^{-1}$ and "wide" - 15$\left.50 \mathrm{~cm}^{-1}\right)$.

Table 2 shows the results of the processing of the experimental DCMSL contours obtained by the decomposition of the experimental contour into components by the method of successive approximations.

As we can see from this table, $\sigma_{1}, \sigma_{2}, \alpha_{1}, \alpha_{2}$ are parameters of the contour components, $\mathfrak{J}$ is the integrated intensity of the total contour in relative units. For $\sigma_{2}$ and $\alpha_{2}$, the accuracy estimation was performed by the method of least squares. For $\sigma_{1}$ and $\mathfrak{J}$, the relative mean square errors of the mean for all the measurement cycle are given.

Analysis of Table 2 shows that the narrow contour $\sigma_{1}$ indicates the strong temperature dependence $\frac{\sigma_{1}\left(200^{\circ} \mathrm{C}\right)}{\sigma_{1}\left(20^{\circ} \mathrm{C}\right)}=3.83$; the wide contour $\sigma_{2}$ weakly depends on the temperature $-\frac{\sigma_{2}\left(200^{\circ} \mathrm{C}\right)}{\sigma_{2}\left(20^{\circ} \mathrm{C}\right)}=1.24$.

Comparison of the theoretical and experimental values of weight for contour components shows that, at room temperature, the values of weights $\alpha_{1}$ and

Table 2

\begin{tabular}{|c|c|c|c|c|c|}
\hline$T,{ }^{\circ} \mathrm{C}$ & $\sigma_{1}, \mathrm{~cm}^{-1}$ & $\sigma_{2}, \mathrm{~cm}^{-1}$ & $\alpha_{1}$ & $\alpha_{2}$ & $\mathfrak{J}$ \\
\hline 20 & 1.20 & 10.00 & 0.67 & 0.33 & 8000 \\
50 & 2.00 & 11.00 & 0.62 & 0.37 & 8500 \\
100 & 2.60 & 12.50 & 0.60 & 0.40 & 8800 \\
150 & 4.60 & 12.40 & 0.54 & 0.46 & 9000 \\
200 & 4.60 & 12.40 & 0.51 & 0.49 & 9300 \\
$\begin{array}{c}\text { The statis- } \\
\text { tical error }\end{array}$ & \pm 0.1 & \pm 0.5 & \pm 0.02 & \pm 0.02 & $1-1.5$ \\
\hline
\end{tabular}

$\alpha_{2}$ are different. With increasing the temperature, the difference is reduced; the further increase of the temperature leads to a divergence again. This may be due to the fact that, in the process of scattering, not only the rotational motion is observed, but also other types of motion, in particular, the vibrational one.

With increasing the temperature, the half-widths of contours increase, and a narrower contour $\sigma_{1}$ expands relatively faster, than a wide contour. The total integrated intensity of DCMSL increases with the temperature. The most interesting result is that the intensities $\mathfrak{J}_{1}=\mathfrak{J} \alpha_{1}$ and $\mathfrak{J}_{2}=\mathfrak{J} \alpha_{2}$, of the narrow and broad components of the Lorentz contours have different signs in the temperature range: at the beginning, they increase with the temperature, and then they decrease. In view of Anselm's theory [11], this corresponds to a positive correlation of molecules on one axis and a negative one on the other one, which results in significant structure details of the short-range order in the liquid.

The temperature dependence of the intensity of these components will be determined by changes in the correlation of the orientations along the corresponding axes. Thus, the temperature measurements allow, in principle, obtaining enough information about the nature of the short-range order in liquids. As a result, a task of direct evaluation of the role of correlations of the intensities of individual components for the anisotropic scattering becomes very urgent. Without such a calculation, the conclusions about the correlations obtained based on [11] from the temperature dependence of the scattering have a conditional character.

1. V.E. Pogorelov, L.A. Bulavin, I. Doroshenko, O. Fesjun, and O. Veretennikov, J. of Mol. Struct. 708, No. 1-3, 61 (2014).

2. N.A. Atamas, A.M. Yaremko, L.A. Bulavin, V.E. Pogorelov, S. Berski, Z. Latajka, H. Ratajczak, and A. AbkowiczBieńko, J. of Mol. Struct. 605, 187 (2002).

3. I.I. Adamenko, L.A. Bulavin, V. Ilyin, S.A. Zelinsky, and K.O. Moroz, J. of Mol. Liquids 127, 90 (2006).

4. L.A. Bulavin, A.I. Fisenko, and N.P. Malomuzh, Chem. Phys. Lett. 453, 183 (2008).

5. P.K. Khabibullaev, L.A. Bulavin, V.E. Pogorelov, F.X. Tuhvatullin, A.I. Lizengevich, Sh.O. Otajonov, and A.J. Jumabaev, The Dynamics of Molecules of the Liquid (Fan, Tashkent, 2009).

ISSN 2071-0194. Ukr. J. Phys. 2015. Vol. 60, No. 8 
6. I.Yu. Doroshenko, V.Ye. Pogorelov, G.A. Pitsevich, and V. Shablinskas, The Dynamics of Molecules of the Liquid (LAMBERT Academic Publ., 2012).

7. L.A. Bulavin, V.Ya. Gotsulskiy, and V.E. Chechko, Ukr. J. Phys. 59, 881 (2014).

8. Sh. Otajonov, B. Eshchanov, and A. Isamatov, Ukr. J. Phys. 59, 254 (2014).

9. Sh. Otajonov, Doctoral thesis (Tashkent, 1992).

10. I.L. Fabelinskii, Molecular Scattering of Light (Nauka, Moscow, 1965) (in Russian).

11. A.I. Anselm, JETP 17, 439 (1947).

Received 01.05.15
Б.Х. Еичанов, Ш. Отажсонов, Н. Солієва, А. Ісаматов

РОЗПОДІЛ ІНТЕНСИВНОСТІ В СПЕКТРІ МОЛЕКУЛЯРНОГО РОЗСІЮВАННЯ СВІТЛА I РЕЛАКСАЦІЙНІ ЯВИЩА В РІДИНАХ

$\mathrm{P}$ е $з$ ю м е

Проаналізовано структуру та форму смуг орієнтаційних спектрів молекулярного розсіювання світла в толуолі. Виявлено можливості їх використання для отримання інформації про особливості взаємодії молекул. Показано, що закономірності, які спостерігаються в розсіянні, можна пояснити, виходячи з механізму загальмованого обертання молекул рідини з урахуванням специфіки міжмолекулярної взаємодії в толуолі. 